\title{
Nanocomposite of Photocurable Epoxy-acrylate Resin and Carbon Nanotubes: Dynamic-mechanical, Thermal and Tribological Properties
}

\author{
Marcos Nunes dos Santos ${ }^{a}$, Carlos Vinícius Opelt ${ }^{a}$, Sérgio Henrique Pezzin ${ }^{a}$, Sandro Campos Amico ${ }^{b}$ \\ César Edil da Costa ${ }^{a}$, Júlio César Milan ${ }^{a}$, Fernando Humel Lafratta ${ }^{a,}$ Luiz, Antonio Ferreira Coelho ${ }^{a *}$ \\ ${ }^{a}$ Pós-graduação em Ciência e Engenharia de Materiais - PGCEM, Universidade do Estado de Santa \\ Catarina - UDESC, Campus Avelino Marcante, s/n, CEP 89223-100, Joinville, SC, Brasil \\ ${ }^{b}$ Pós-graduação em Engenharia de Minas, Metalúrgica e de Materiais - PPGE3M, \\ Universidade Federal do Rio Grande do Sul - UFRGS, Av. Bento Gonçalves, 9500, \\ CEP 91501-970, Porto Alegre, RS, Brasil
}

Received: July 8, 2012; Revised: September 7, 2012

In this study, the thermal, dynamic-mechanical and tribological behavior of nanocomposites of a photocurable epoxy-acrylate resin and multiwalled carbon nanotubes (MWCNT) are investigated. A route consisting of a combination of sonication, mechanical and magnetic stirring is used to disperse 0.25-0.75 wt. (\%) MWCNT into the resin. Two photocuring cycles using 12 hours and 24 hours of UV-A radiation are studied. The storage modulus, the loss modulus and the tan delta are obtained by dynamic mechanical analysis. Thermal stability is investigated by thermogravimetry, morphology by transmission electronic microscopy (TEM) and tribological performance using a pin-on-disk apparatus. The results indicate an increase in stiffness and higher ability to dissipate energy, as well as a shift in the glass transition temperature for the nanocomposites. The addition of nanofillers also decreased friction coefficient and wear rate of the nanocomposites but did not change the observed wear mechanisms.

Keywords: nanocomposite, photocuring, epoxy-acrylate, carbon nanotubes

\section{Introduction}

Most of the work in tribology and wear, based either on micro or nanoscale, focuses on metals and ceramics. Polymeric materials and their nanocomposites have only been receiving more attention in the last few years, especially due to the possibility to replace traditionally used materials at lower cost. Nevertheless, there is lack of experimental data in the tribology and wear area for these materials ${ }^{1}$.

Carbon nanotubes (CNT) have being massively studied since their discovery in the beginning of last decade, especially due to their extraordinary and unprecedented mechanical and transport properties. Small amounts of CNT, in general within 0.1-5.0 wt. (\%), are added to the polymeric matrix aiming to improve mechanical, thermal and tribological properties ${ }^{2,3,4}$. Although, as pointed out by Dasari et al. ${ }^{1}$, it cannot be assumed that nanofillers always improve wear/scratch (and friction) properties.

Photocurable resins are a very important class of thermosets, particularly due to their acrylate, metacrylate or epoxy groups. One of their main advantages is the rapid cure by means of radiation. In addition, they present chemical and corrosion resistance, high modulus, and thermal and dimensional stability ${ }^{5-6}$, being often employed in aeronautical, biomedical and microelectronic industries, especially those that use stereolitography ${ }^{6-8}$.

*e-mail: lcoelho@joinville.udesc.br
Some papers focusing on photocurable resins include: Sangermano et al. ${ }^{9}$, who added 0.025-0.1 wt. (\%) single walled carbon nanotubes (SWCNT) to an epoxy resin and obtained an increase from 197 to $210^{\circ} \mathrm{C}$ in $\mathrm{T}_{\mathrm{g}}$. Zhu et al. ${ }^{10}$ studied an epoxy resin reinforced with $0.5 \mathrm{wt}$. (\%) MWCNT and reported 35\% increase in Young's Modulus. MartinGallego et al. ${ }^{11}$ studied several carbon fillers (e.g. graphite, graphene and CNT) and found that they delayed the curing reaction of a cationically photocurable epoxy and yielded an increase (higher than $20^{\circ} \mathrm{C}$ ) in the glass transition temperature $\left(\mathrm{T}_{\mathrm{g}}\right)$. Also, Dos Santos ${ }^{12}$ analyzed the thermal and mechanical behavior of an epoxyacrylate resin with MWCNT and reported an increase in stiffness and hardness and a shift in $\mathrm{T}_{\mathrm{g}}$.

In this work, nanocomposites of an epoxy-acrylate resin were prepared with 0.25-0.75 wt. (\%) MWCNTs, photocured under UV-A radiation for 12 and 24 hours. Their dynamic-mechanical, morphological and especially tribological properties (friction coefficient and wear rate) were evaluated in order to assess the influence of the CNT and the curing time on these characteristics.

\section{Experimental}

An epoxy/acrylate photocurable resin, SOMOS 10220 (multiacrylate monomers $45-50 \%$, epoxies $15-25 \%$, polyols $20-35 \%$, and photoinitiators $0.2-5.0 \mathrm{wt}$ (\%)), supplied by DSM, was used to prepare neat resin samples 
and nanocomposite samples with 0.25 and 0.75 wt. (\%) MWCNT Bayer - Baytubes - C150P (average length of 1-10 $\mu \mathrm{m}$ and outer mean diameter of 13-16 nm). The resin is a mixture of epoxy oligomer and acrylate monomer.

Dispersion of MWCNTs was carried out by a combination of sonication (model Sonics Vibra Cell, $750 \mathrm{~W}$ ), mechanical and magnetic stirring ${ }^{4}$. The overall sonication time was 24 minutes, divided into sixteen 90 s-cycles intercalated with 15 secondsrest to avoid overheating of the 40-g epoxy sample, mechanical (50 rpm) and magnetic stirring were also employed at the same time. The sonication equipment was the ultrasound tip (Sonics Vibration, $20 \mathrm{kHz}$ ), working at $180 \mathrm{~W}$ of power.

Samples with $0.5 \pm 0.1 \mathrm{~mm}$ of thickness were photocured for 12 and 24 hours using UV-A (355 nm) lamps (intensity of $0.08 \mathrm{~W} . \mathrm{cm}^{-2}$ ) - temperature of $40{ }^{\circ} \mathrm{C}$. Transmission electronic microscopy (TEM) analysis of the dispersions was performed in JEOL - JEM ExII $(120 \mathrm{kV})$ equipment.

Thermogravimetric analysis (TGA) was carried out up to $600{ }^{\circ} \mathrm{C}$ under a heating rate of $10{ }^{\circ} \mathrm{C} / \mathrm{min}$ in a NETZSCH STA 449C equipment. Dynamic mechanical analysis (DMA) was carried out in a TA Instruments 2980 DMA V1 7B (frequency of $1 \mathrm{~Hz}$ and heating rate of $3{ }^{\circ} \mathrm{C} / \mathrm{min}$ ), from 35 to $250^{\circ} \mathrm{C}$, using samples of the following dimensions: $11.0( \pm 2.0) \times 6.0( \pm 1.2) \times 0.40( \pm 0.08) \mathrm{mm}$. Scanning electron microscopy (SEM) of the samples was performed in a Zeiss model DSM 940 to $20 \mathrm{kV}$ microscope, using gold-coated samples (gold layer: c.a. $25 \mathrm{~nm}$ ).

Pin-on-disc sliding wear tests were carried out using an in-house built tribometer named TRIBOM CZ1000. The test parameters were: $5.0 \mathrm{~N}$ load, $0.1 \mathrm{~m} / \mathrm{s}$ sliding speed and $1000 \mathrm{~m}$ sliding distance. AISI 52100 spheres of $6.0 \mathrm{~mm}$ diameter were used as counter surface. Test temperature was $24.0 \pm 3.0^{\circ} \mathrm{C}$ and humidity was kept lower than $30 \%$. The friction force was measured and the friction coefficient was calculated. Profiles of the wear tracks were obtained using CSV-2000 perfilometer, sensor with $25.0 \mu \mathrm{m}$ radius and $12.0^{\circ}$ slope angle, using $25.0( \pm 5.0) \mathrm{mN}$ load, and $0.5 \mathrm{~mm} / \mathrm{s}$ displacement speed. The volume of removed material was calculated with the aid of dedicated software.

\section{Results and Discussion}

\subsection{General characteristics}

Figure 1 shows the TG curves of all samples. The addition of MWCNT did not cause any significant change in the reference curves. Mass losses initiated around $300^{\circ} \mathrm{C}$, with a $\mathrm{T}_{\text {onset }}$, defined as the inflection point in the curves shown in this figure, around $373{ }^{\circ} \mathrm{C}$ and with $\mathrm{T}_{\text {end }}$ within $446-451^{\circ} \mathrm{C}$.

TEM-images showed that bundles of CNT, even after sonication, are still presented in the nanocomposite. Dispersion of the nanotubes, as observed by TEM (Figure 2), showed similarities with the work of Gojny et al. ${ }^{13}$, which applied calenders for CNT dispersion. In both, some degree of exfoliation can be found in the nanocomposites.

Figure $3 \mathrm{a}, \mathrm{b}$ and Table 1 show the storage modulus results obtained for all samples. For 12 hours photocuring, the increase over the neat resin achieved $33 \%$ and $28 \%$ for $0.25 \%$ and 0.75 wt. (\%) MWCNT, respectively. For 24 hours the increase was even higher, $76 \%$ and $154 \%$ for 0.25 and 0.75 wt. (\%) MWCNT, respectively. Certainly, the addition of CNT contributes to raise storage modulus and, consequently, stiffness of the composite. Zhou et al. ${ }^{14}$ obtained an increase of $93 \%$ in storage modulus when adding 0.4 wt. (\%) CNT to an epoxy resin, whereas Zhu et al. ${ }^{10}$ obtained an increase of up to $35 \%$ when adding $0.5 \mathrm{wt}$. (\%) MWCNT to a photocurable epoxy resin. A huge increase in E' of $1100 \%$ (from 2.5 to $31.0 \mathrm{GPa}$ ) was reported by Hwang et al. ${ }^{15}$ when adding $20 \mathrm{wt}$. (\%) MWCNT to a PMMA matrix, a thermoplastic polymer, which was justified by the strong interaction between the NT's and the PMMA structure, increasing load transfer between them.

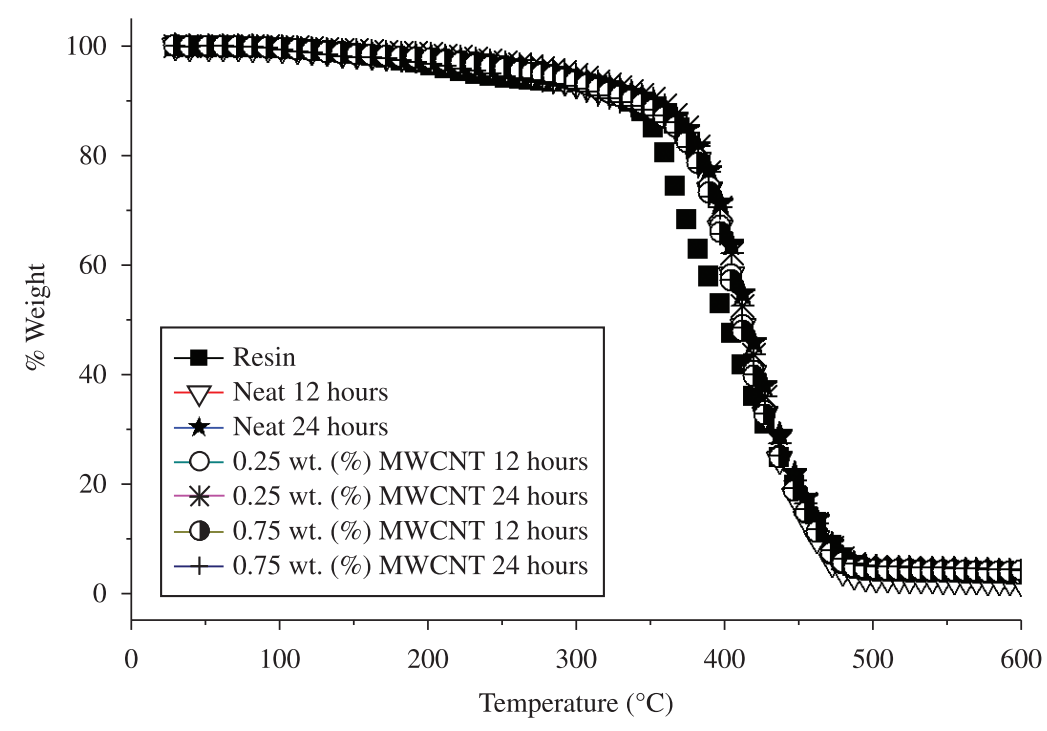

Figure 1. TGA curves for all nanocomposites. 


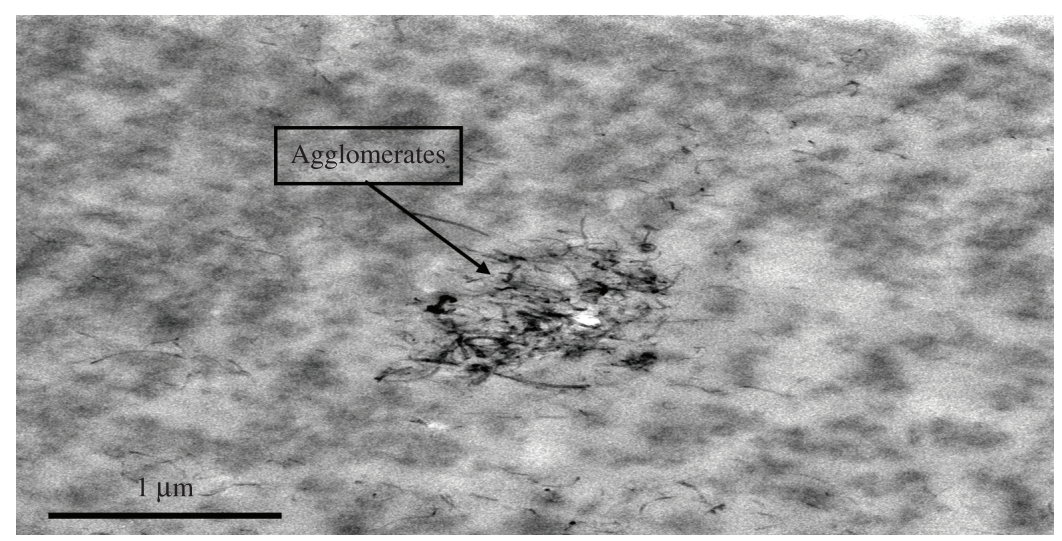

Figure 2. Remaining agglomerates in TEM images after sonication showing a mostly exfoliated structure.

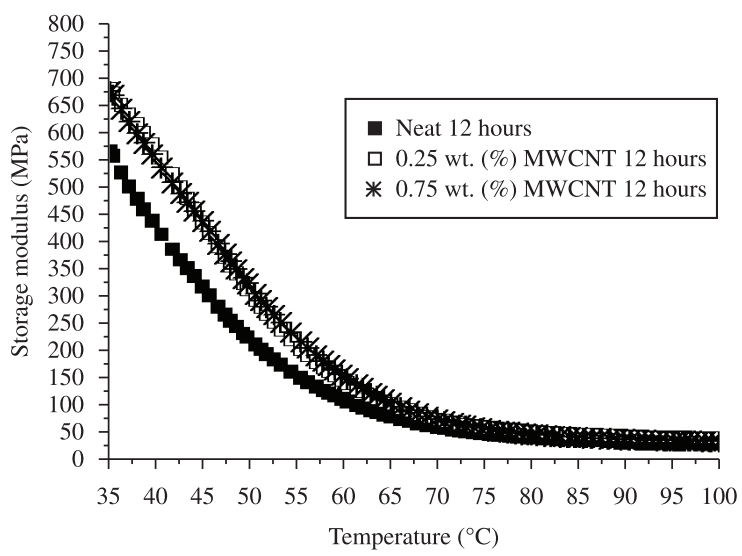

(a)

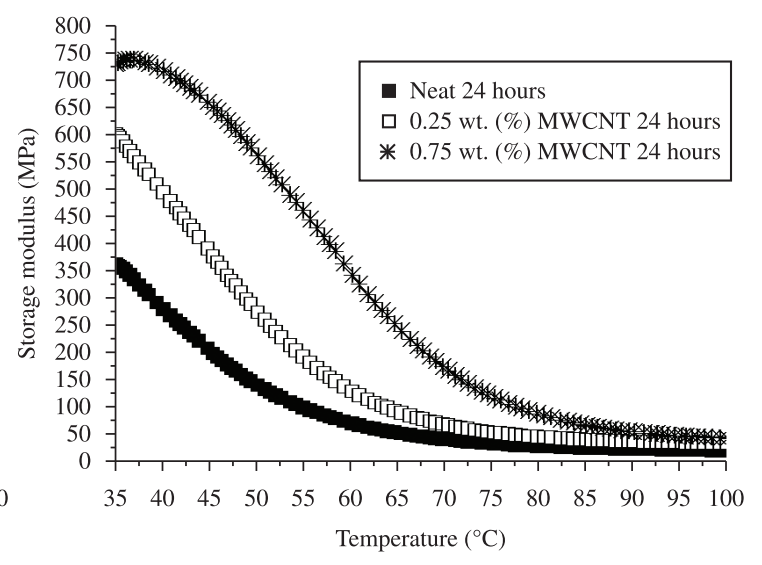

(b)

Figure 3. Storage modulus for neat resin and composites for: (a) 12 hours and (b) 24 hours of curing.

Table 1. DMA results for the neat resin and the nanocomposites.

\begin{tabular}{lccc}
\hline \multicolumn{1}{c}{ Samples } & $\begin{array}{c}\text { Storage } \\
\text { Modulus }^{\mathbf{1}} \\
(\mathbf{M P a})\end{array}$ & $\begin{array}{c}\text { Loss } \\
\text { Modulus }^{1} \\
(\mathbf{M P a})\end{array}$ & $\begin{array}{c}\mathbf{T}_{\mathrm{g}} \\
\left({ }^{\circ} \mathbf{C}\right)\end{array}$ \\
\hline NEAT 12 hours & 428 & 141 & 55 \\
0.25 wt. (\%) MWCNT 12 hours & 570 & 166 & 58 \\
0.75 wt. (\%) MWCNT 12 hours & 551 & 154 & 63 \\
NEAT 24 hours & 288 & 110 & 53 \\
0.25 wt. (\%) MWCNT 24 hours & 507 & 135 & 58 \\
0.75 wt. (\%) MWCNT 24 hours & 732 & 152 & 68 \\
\hline
\end{tabular}

${ }^{1}$ Data taken at $40{ }^{\circ} \mathrm{C}$.

Figure $4 \mathrm{a}, \mathrm{b}$ and Table 1 show the loss modulus results obtained for all samples. For 12 hours, the increase over the neat resin achieved $18 \%$ and $9 \%$, when adding 0.25 and 0.75 wt. (\%) MWCNT, respectively. For 24 hours, the increase over the neat resin achieved $23 \%$ and $38 \%$ when adding 0.25 and 0.75 wt. (\%) MWCNT, respectively. For both cases ( 0.25 and 0.75 wt. (\%) CNT) addition of CNT contributes to increase energy dissipation as heat ${ }^{16}$.
Figure 5a, b and Table 1 show the tan delta graphs used to calculate $\mathrm{T}_{\mathrm{g}}$ for all samples. For 12 hours curing, an increase of up to $7.5{ }^{\circ} \mathrm{C}$ in $\mathrm{T}_{\mathrm{g}}$ was found when adding 0.75 wt. (\%) MWCNT. For 24 hours curing, the increase in $\mathrm{T}_{\mathrm{g}}$ reached $15^{\circ} \mathrm{C}$ for the 0.75 wt. (\%) MWCNT sample.

\subsection{Friction and wear}

The friction coefficient results for all samples are presented in Figure 6a. The lowest friction coefficient $(0.39 \pm 0.02)$ was obtained for nanocomposites with 0.25 wt. (\%) of MWCNT cured for 12 hours, a reduction of $24 \%$ compared to the respective neat resin. For the samples cured for 24 hours, the greater reduction $(17 \%)$ in friction coefficient was also obtained for the $0.25 \mathrm{wt}$. (\%) of MWCNT sample. These results may be explained by the fact that carbon nanotubes show self-lubricating properties, as reported by Sulong et al. ${ }^{16}$. Sangermano et al. ${ }^{9}$ also obtained a reduction in friction coefficient (from 0.42 to 0.38 ) for nanocomposites comprised of a photocurable resin with 0.10 wt. (\%) SWCNT in comparison with the neat resin.

Nevertheless, in this work, the friction coefficient increased for higher MWCNT content, which may be a consequence of the presence of a higher amount of CNT 
bundles (agglomerates). In this case, there would be a greater tendency for matrix fragmentation, leading to the production of loose wear debris at the contact interface, which would increase the friction coefficient. Agglomerates in isolated regions of the matrix may also mean that there is lack of CNT in other regions of the matrix, which therefore would not

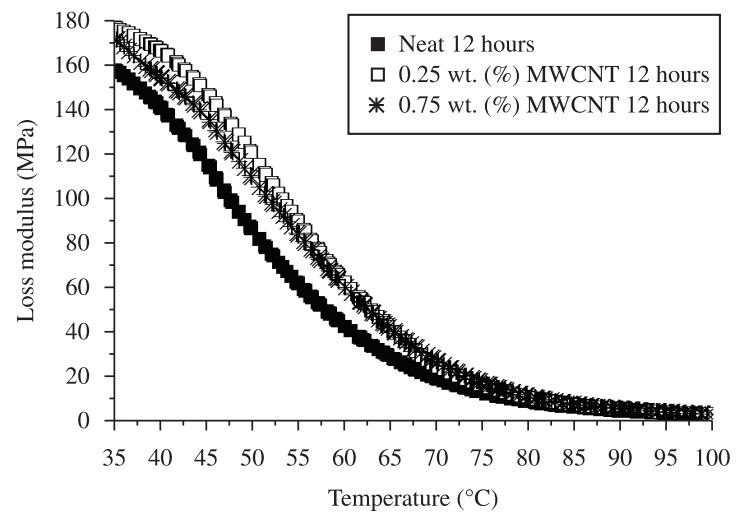

(a)

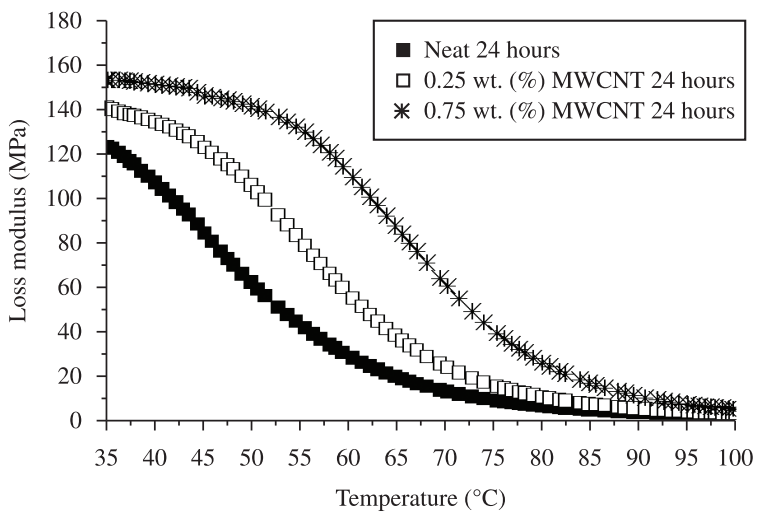

(b)

Figure 4. Loss modulus for neat resin and composites for: (a) 12 hours and (b) 24 hours of curing.

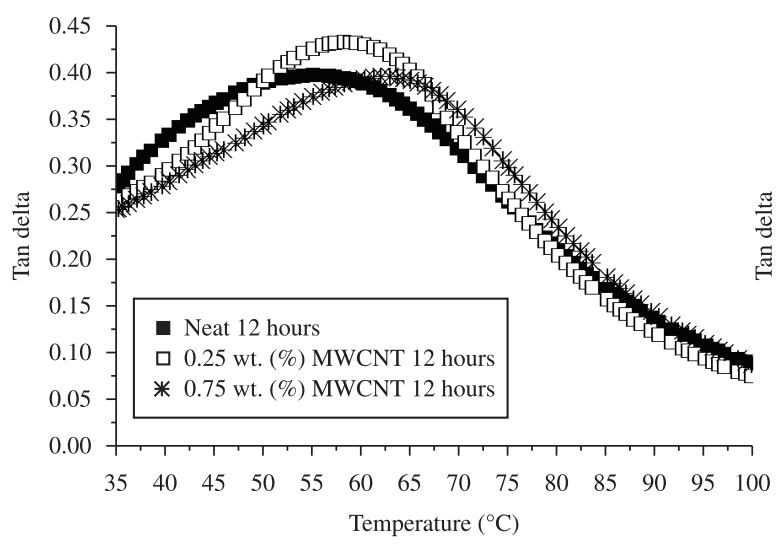

(a)

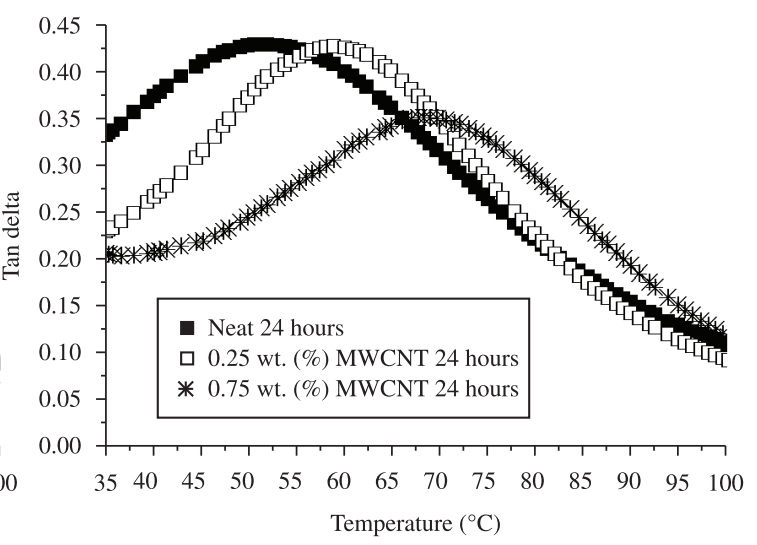

(b)

Figure 5. Tan delta for neat resin and composites for: (a) 12 hours and (b) 24 hours of curing.

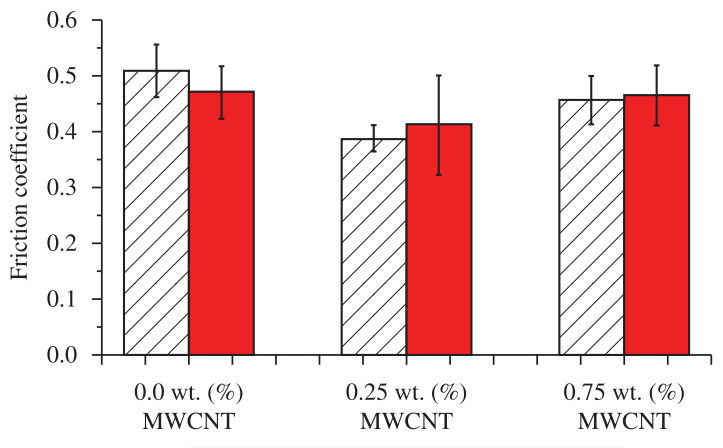

$\square 12$ hours curing $\square 24$ hours curing

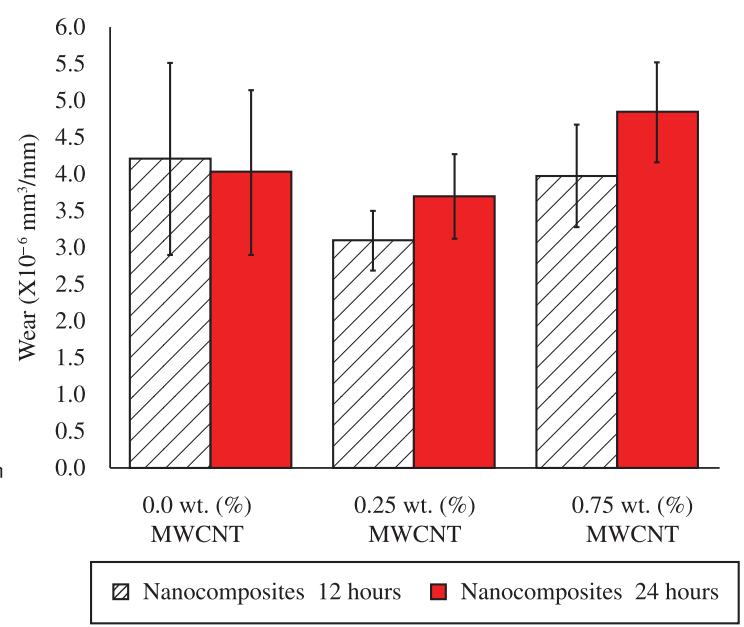

(b)

Figure 6. Friction coefficient (a) and wear rate (b) for the epoxy-acrylate based materials. 
be able to produce a continuous carbonaceous film during sliding that would protect the contact surfaces ${ }^{17}$.

A perfilometer was used to evaluate wear of all samples submitted to pin-on-disk testing. Figure $6 \mathrm{~b}$ shows that the wear results followed the trends observed for the friction coefficient, i.e. a reduction in wear rate was obtained for the samples with lower friction coefficient. The reduction in wear reached $24 \%$ and $8 \%$ for the $0.25 \mathrm{wt}$. (\%) MWCNT samples cured for 12 and 24 hours, respectively, in comparison to the respective neat resins.

SEM images of the wear tracks of the surfaces of the samples after testing are shown in Figures 7-10. Figure 7, for the neat epoxy acrylate and the composites cured for 12 hours, shows regions of non-uniform roughness and flat regions in all samples. Risks or wear grooves are not observed, which is characteristic of abrasive wear. In addition, SEM images taken at higher magnification (Figure 8) indicate adhesive wear, which is characteristic of epoxy resin ${ }^{18}$. These samples also show some wear debris and transverse cracks, characterizing surface fatigue, which is typical of brittle materials such as epoxy ${ }^{19}$. As reported by Romanes et al. ${ }^{20}$, surface cracks, conversion of broken waves, surface fatigue delamination and debris production are all characteristic of epoxy-based materials.

In this study, for the neat samples, polymeric material was transferred to the metal sphere due to very high temperatures involved. At the same time, some of this adhered material detached from the metal surface during testing and was transferred to the resin itself, characterizing an adhesive wear. The presence of cracks implies surface fatigue wear in the nanocomposite samples, and, in these cases, wear was a result of free particles (including CNT + epoxy-acrylate) and asperities in contact. Similar aspects of surface fatigue are found in the work of Jacobs et al. ${ }^{19}$.

SEM images of the wear tracks of the surfaces of the 24 hours curing samples after testing are shown in Figure 9. These figures show regions of non-uniform roughness for all samples, similar to what was found for 12 hours curing samples. In addition, no risks were observed in the eroded samples. At higher magnification (Figure 10), these regions also show adhesive wear, i.e. the transfer of polymeric material to the beads used on the pin-on-disc tests. There is also some wear debris in the samples, similar to the samples cured at 12 hours. Energy dispersive X-ray (EDS) analysis (Figure 11) shows a great amount of carbon, from the

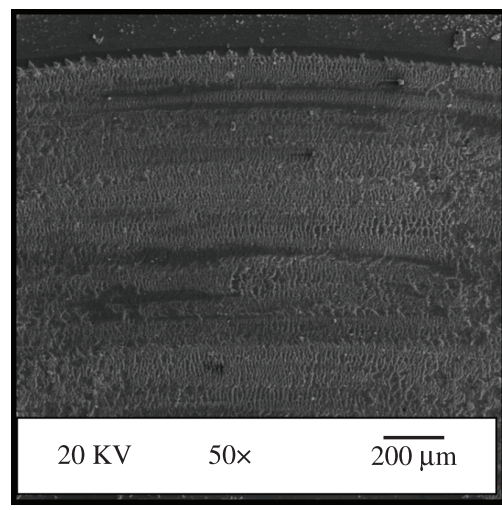

(a)

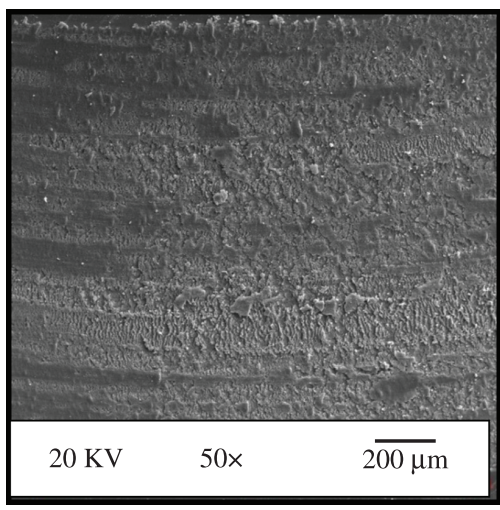

(b)

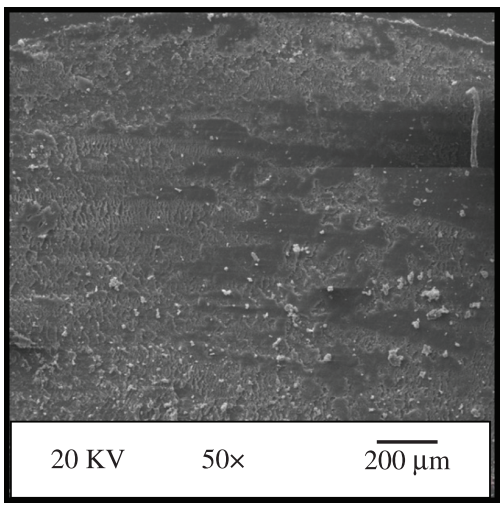

(c)

Figure 7. SEM images of wear track regions for: a) neat resin, b) 0.25 wt. (\%) MWCNT, and c) 0.75 wt. (\%) MWCNT. All samples cured for 12 hours and $50 \times$ magnification.

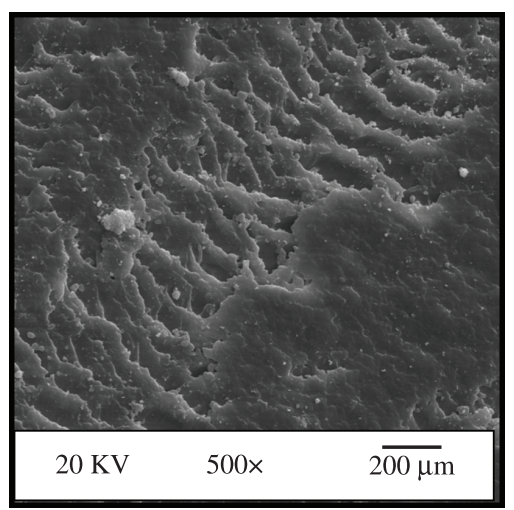

(a)

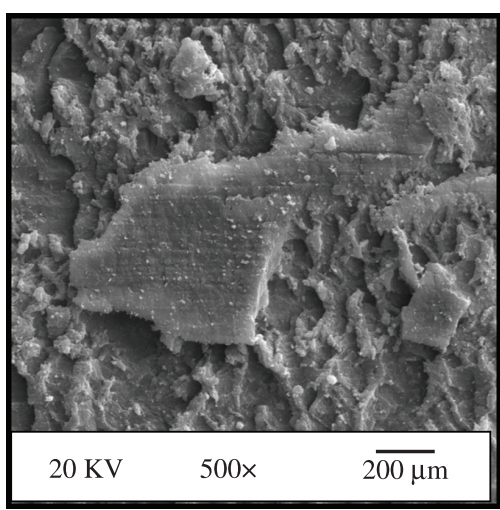

(b)

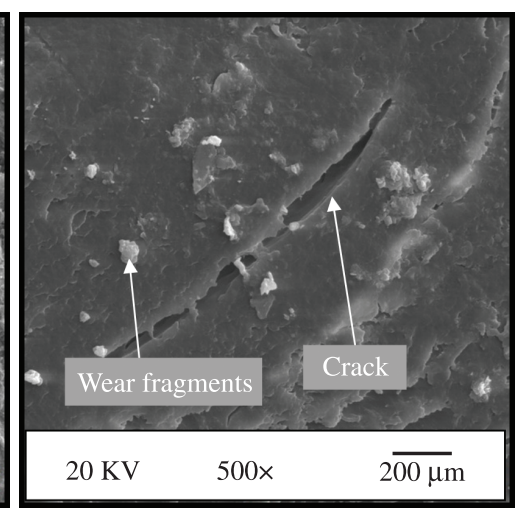

(c)

Figure 8. SEM images of wear track regions for: a) neat resin, b) 0.25 wt. (\%) MWCNT, and c) 0.75 wt. (\%) MWCNT. All samples cured for 12 hours and $500 \times$ magnification. 


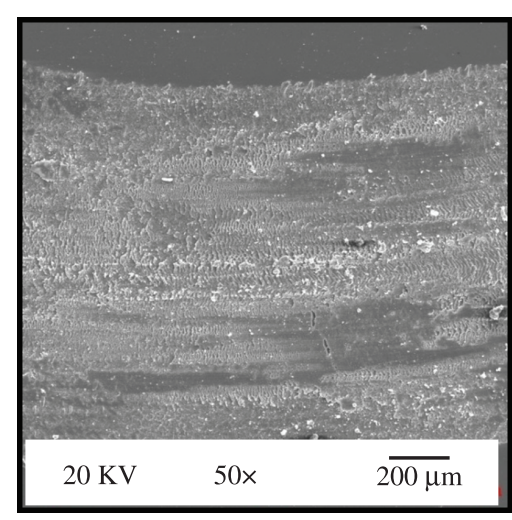

(a)

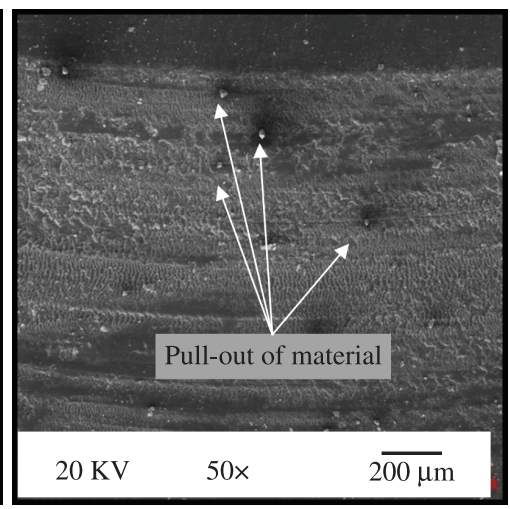

(b)

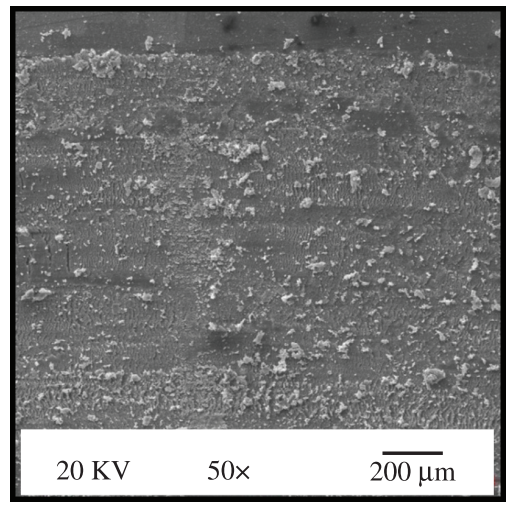

(c)

Figure 9. SEM images of wear track regions for: a) neat resin, b) 0.25 wt. (\%) MWCNT, and c) 0.75 wt. (\%) MWCNT. All samples cured for 24 hours and 50× magnification.

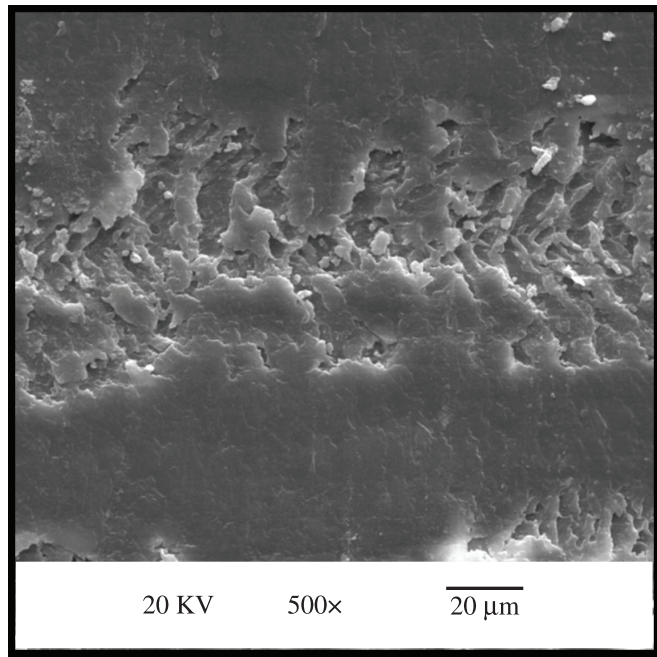

(a)

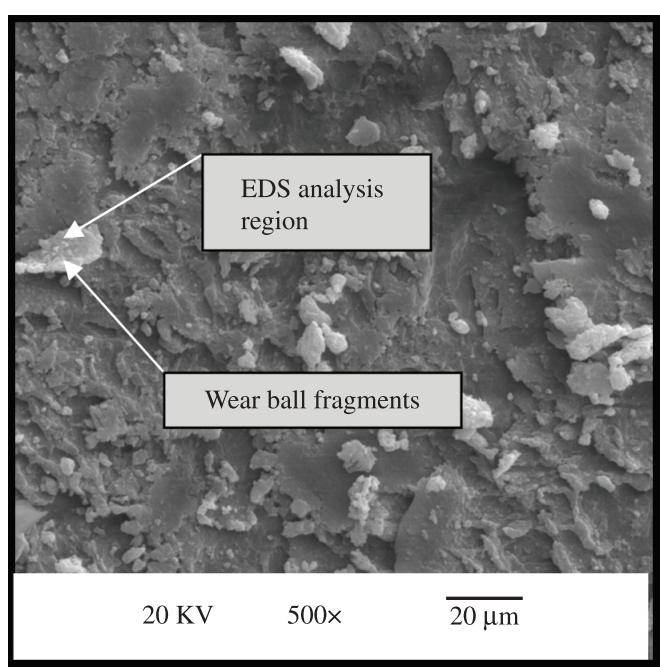

(b)

Figure 10. SEM images of wear track regions for: a) neat resin, and b) 0.25 wt. (\%) MWCNT. All samples cured for 24 hours and 500x magnification.

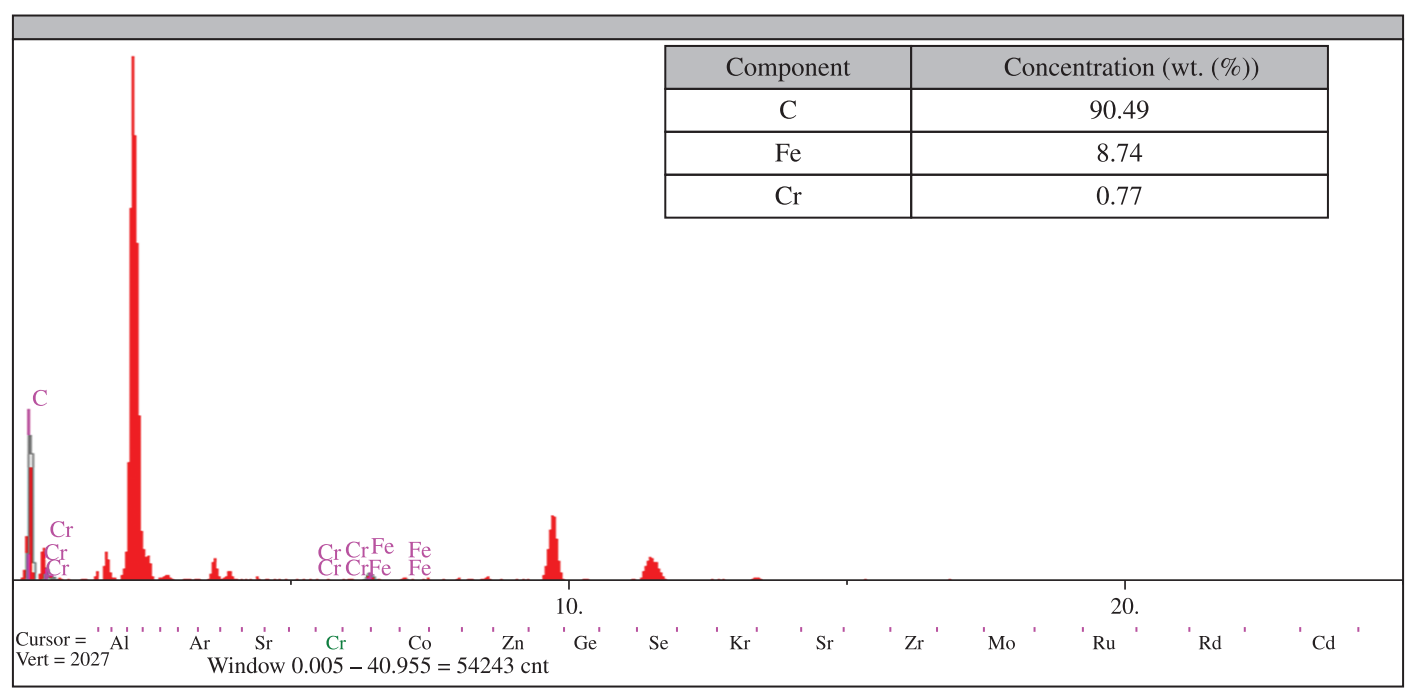

Figure 11. EDS results of the wear debris observed in the wear region shown in Figure 12b. 


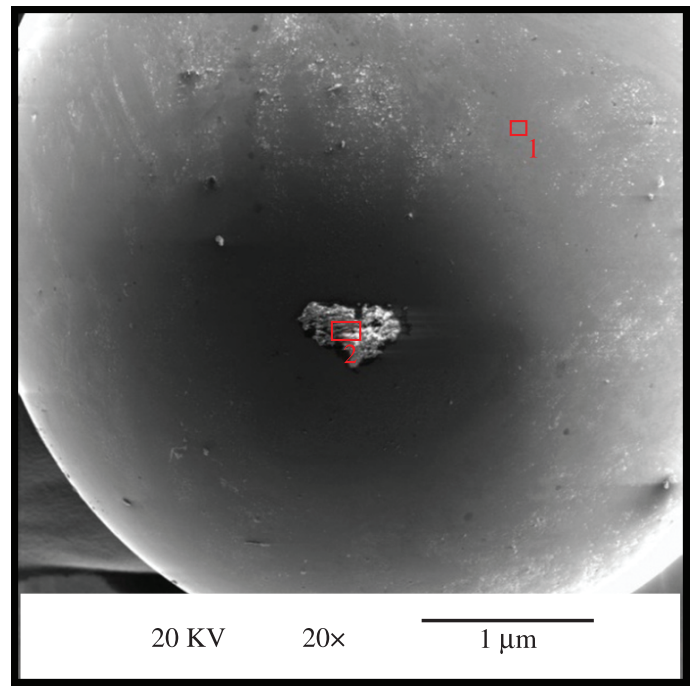

(a)

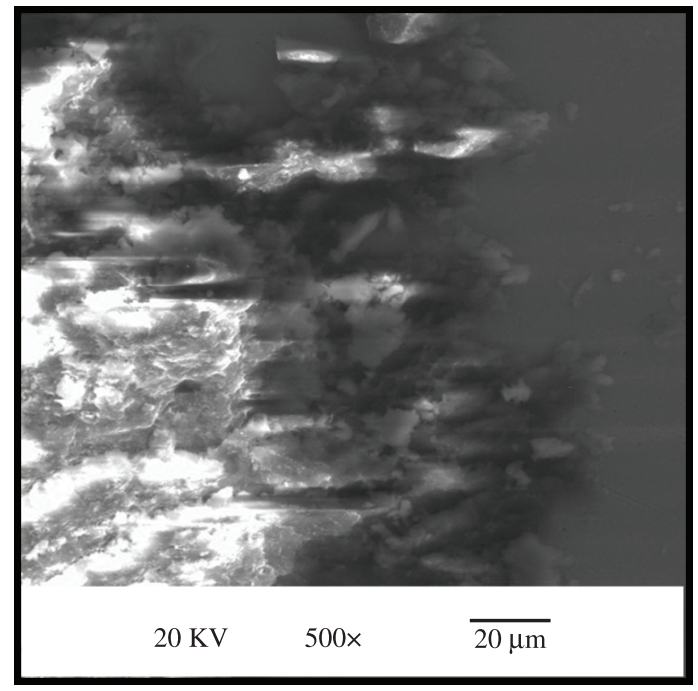

(b)

Figure 12. SEM of the cleaned spherical surface after testing with 0.25 wt. (\%) MWCNT (12 hours curing): a) general appearance, and b) interface between the adhered polymeric material and the wear region of the ball.

Table 2. EDS results of the wear regions 1 and 2 shown in Figure 12a.

\begin{tabular}{ccc}
\hline Component & $\begin{array}{c}\text { Concentration } \\
(\text { wt. }(\%))-\text { Region 1 }\end{array}$ & $\begin{array}{c}\text { Concentration } \\
(\text { wt. (\%)) - Region 2 }\end{array}$ \\
\hline $\mathrm{Fe}$ & 98.07 & --- \\
$\mathrm{Cr}$ & 1.09 & --- \\
$\mathrm{C}$ & 0.84 & 61.83 \\
$\mathrm{O}$ & --- & 38.17 \\
\hline
\end{tabular}

polymer, and a small content of iron and chromium, from the 52100 chrome steel sphere of the pin used in the test.

Figures 12a, b shows SEM pictures of the wear regions of the beads used in the wear tests. Even after cleaning of the metal surface with cotton, polymeric material is still adhered to it. This is further confirmed by the results (Table 2 ) of the EDS analysis of regions 1 and 2 of Figure $12 \mathrm{a}(0.25 \mathrm{wt}$. (\%) MWCNT sample). Region 1 is predominantly comprised of iron and chromium, i.e. it is the steel sphere whereas Region 2 has only carbon and oxygen, i.e. from the polymeric resin. This indicates that there was adhesive wear in the samples under study, and that polymer-polymer contact is expected.

\section{Conclusions}

Two different contents of MWCNT were used to produce nanocomposites with a photocurable epoxy-acrylate resin. In both cases, a nanocomposite with superior mechanical properties was obtained. The most significant reinforcement effect was observed with 0.75 wt. (\%) MWCNT cured for
24 hours, where $\mathrm{E}^{\prime}$ increased $154 \%$ in relation to the neat resin. The $\mathrm{T}_{\mathrm{g}}$ increased $10^{\circ} \mathrm{C}$ when MWCNTs were added to the matrix, but TGA did not show significant changes in thermal stability. Nevertheless, TEM showed some CNT bundles in the nanocomposite even after harsh sonication.

Tribological studies revealed that the addition of NT decreases wear and friction coefficient. The best result was achieved with 0.25 wt. (\%) MWCNTs, with 12 hours of UV-A curing, which yielded $24 \%$ and $17 \%$ reduction in wear rate and friction coefficient, respectively. However, for larger MWCNT content, wear and friction coefficient may increase, especially when CNT clusters (non-homogeneous dispersion) in the matrix occurs. The wear mechanisms found for the nanocomposites were: adhesive wear, fatigue and delamination. These mechanisms are commonly found in most epoxy materials.

The results obtained for the nanocomposites studied in this work are consistent with the literature involving epoxy polymer matrices with CNT. The present results suggest that these nanocomposites may have potential applications as materials used for energy dissipation and as coatings.

\section{Acknowledgements}

The authors would like to thank the Brazilian Space Agency (AEB Uniespaço) and $\mathrm{CNPq}$ for the financial support, CAPES-DS for the scholarship to the post-graduate student Marcos Nunes dos Santos, ROBTEC for providing the resin and Bayer for providing MWCNTs. 


\section{References}

1. Dasari A, Yu ZZ and Mai YW. Fundamental aspects and recent progress on wear/scratch damage in polymer nanocomposites. Materials Science \& Engineering R-Reports. 2009; 63(2):3180. http://dx.doi.org/10.1016/j.mser.2008.10.001

2. Micusik M, Omastova M, Krupa I, Prokes J, Pissis P, Logakis E et al. A comparative study on the electrical and mechanical behaviour of multi-walled carbon nanotube composites prepared by diluting a masterbatch with various types of polypropylenes. Journal of Applied Polymer Science. 2009; 113(4):2536-2551. http://dx.doi.org/10.1002/app.30418

3. Chou TW, Gao LM, Thostenson ET, Zhang ZG and Byun $\mathrm{JH}$. An assessment of the science and technology of carbon nanotube-based fibers and composites. Composites Science and Technology. 2010; 70(1):1-19. http://dx.doi.org/10.1016/j. compscitech.2009.10.004

4. Loos MR, Pezzin SH, Amico SC, Bergmann CP and Coelho LAF. The matrix stiffness role on tensile and thermal properties of carbon nanotubes/epoxy composites. Journal of Materials Science. 2008; 43(18):6064-6069. http://dx.doi.org/10.1007/ s10853-008-2960-z

5. Riegel IC, Freitas LL and Samios D. Envelhecimento físico de sistemas DGEBA/DDM investigado por análise térmica (DSC/ DMA). Polímeros. 1999; 9(3):58-64. http://dx.doi.org/10.1590/ S0104-14281999000300011

6. Andrzejewska E and Andrzejewski M. Polymerization kinetics of photocurable acrylic resins. Journal of Polymer Science Part A: Polymer Chemistry. 1998; 36(4):665-673. http:// dx.doi.org/10.1002/(SICI)1099-0518(199803)36:4<665::AIDPOLA15>3.0.CO;2-K

7. Klauss P. Processos de cura e de decomposição térmica da resina renshap sl 5260 utilizada em fabricação rápida por estereolitografia. [Dissertação]. Florianópolis: Universidade Federal de Santa Catarina; 2006.

8. Stampfl J, Woss A, Seidler S, Fouad H, Pisaipan A, Schwager F et al. Water soluble, photocurable resins for rapid prototyping applications. Macromolecular Symposia. 2004; 217:99-107. http://dx.doi.org/10.1002/masy.200451308

9. Sangermano M, Borella E, Priola A, Messori M, Taurino R and Potschke P. Use of single-walled carbon nanotubes as reinforcing fillers in UV-curable epoxy systems. Macromolecular Materials and Engineering. 2008; 293(8):708-713. http:// dx.doi.org/10.1002/mame.200800126

10. Zhu YF, Ma C, Zhang W, Zhang RP, Koratkar N and Liang J. Alignment of multiwalled carbon nanotubes in bulk epoxy composites via electric field. Journal of Applied Physics. 2009; 105(5):1-6. http://dx.doi.org/10.1063/1.3080243

11. Martin-Gallego M, Hernandez M, Lorenzo V, Verdejo R, Lopez-Manchado MA and Sangermano M. Cationic photocured epoxy nanocomposites filled with different carbon fillers. Polymer. 2012; 53(9):1831-1838. http://dx.doi. org/10.1016/j.polymer.2012.02.054

12. Dos Santos MN, Opelt CV, Lafratta FH, Lepienski CM, Pezzin $\mathrm{SH}$ and Coelho LAF. Thermal and mechanical properties of a nanocomposite of a photocurable epoxy-acrylate resin and multiwalled carbon nanotubes. Materials Science and Engineering A: Structural Materials Properties Microstructure and Processing. 2011; 528(13-14):4318-4324. http://dx.doi. org/10.1016/j.msea.2011.02.036

13. Gojny FH, Wichmann MHG, Kopke U, Fiedler B and Schulte K. Carbon nanotube-reinforced epoxy-compo sites: enhanced stiffness and fracture toughness at low nanotube content. Composites Science and Technology. 2004; 64(15):2363-2371. http://dx.doi.org/10.1016/j.compscitech.2004.04.002

14. Zhou YX, Pervin F, Lewis L and Jeelani S. Experimental study on the thermal and mechanical properties of multiwalled carbon nanotube-reinforced epoxy. Materials Science and Engineering A: Structural Materials Properties Microstructure and Processing. 2007; 452:657-664. http:// dx.doi.org/10.1016/j.msea.2006.11.066

15. Hwang GL, Shieh YT and Hwang KC. Efficient load transfer to polymer-grafted multiwalled carbon nanotubes in polymer composites. Advanced Functional Materials. 2004; 14(5):487491. http://dx.doi.org/10.1002/adfm.200305382

16. Sulong AB, Park J, Lee N and Goak J. Wear Behaviour of Functionalized Multiwalled Carbon Nanotube Reinforced Epoxy Matriz Composites. Journal of Composite Materials. 2006; 40; 1947-1960. http://dx.doi. org/10.1177/0021998306061305

17. Rajkumar K and Aravindan S. Tribological studies on microwave sintered copper-carbon nanotube composites. Wear. 2011; 270(9-10):613-621. http://dx.doi.org/10.1016/j. wear.2011.01.017

18. Dong B, Yang Z, Huang Y and Li HL. Study on tribological properties of multi-walled carbon nanotubes/epoxy resin nanocomposites. Tribology Letters. 2005; 20(3-4):251-254. http://dx.doi.org/10.1007/s11249-005-8637-8

19. Jacobs O, Xu W, Schadel B and Wu W. Wear behaviour of carbon nanotube reinforced epoxy resin composites. Tribology Letters. 2006; 23(1):65-75. http://dx.doi.org/10.1007/s11249006-9042-7

20. Romanes MC, Souza NAD, Coutinho D, Balkus KJ and Scharf TW. Surface and subsurface characterization of epoxymesoporous silica composites to clarify tribological properties. Wear. 2007; 265(1-2):88-96. http://dx.doi.org/10.1016/j. wear.2007.08.022 